\title{
USCF ADOPTS NEW REGULATIONS CONCERNING COMPUTER CHESS
}

During the USCF Convention, August 14-15, 1982, the USCF Board of Delegates adopted new regulations on computer participation in USCF events. These are combined with those previous regulations which remain in effect, in the following presentation of the USCF regulations on Computer Chess, effective August 15, 1982 except where noted:

\section{MEMBERSHIP}

Computer programs may be registered by the originator or the legal owner of the program, as Computer Members of the USCF. The dues for Computer Members shall be the same as for regular adult members. The rights and privileges of Computer Members include and are limited to: the right to play in USCF tournaments subject to USCF regulations on computer participation; the right to acquire an official USCF rating; and a subscription to Chess Life magazine. Specific identification and registration procedures shall be determined administratively.

\section{SALE OF MERBERSHIP}

Computer memberships may be sold only by the USCF office. Owners may be required to sign a statement agreeing to specific rules.

\section{PARTICIPATION IN TOURNAMENTS}

For a period of one year, from Jan. 1, 1983 to Jan. 1, 1984, all tournaments advertised in Chess Life shall be designated as "C" (Computers allowed) or "NC" (No Computers), and the default shall be "C" if neither is specified by the organizer. Computer entries must be arranged in advance, and no director is obligated to accept the entry of any particular computer.

\section{PAIRINGS}

The director shall announce to the participants the presence of one or more computer entrants in a tournament. Within a reasonable time after this announcement, a player has the right to request the director not to pair him with a computer. The director should avoid such a pairing unless the pairing is forced.

\section{ELIGIBILITY FOR PRIZES}

Computers may win only prizes specifically designated for them. Other prizes shall be distributed as though computers were not entered.

\section{RATINGS}

In a tournament with human and computer participants, games between computers shall be rated. Directors should avoid pairing two computers when such pairing would result in a computer playing more than haif its games against other computers. Events in which only computers participate will be rated at the USCF's discretion, except that matches involving computers will not be rated.

\section{CONSULTATION}

A player who consults a computer for advice about his game shall be subject to the same penalties that he would receive for asking advice from a friend. 